\title{
The development of deaf legal discourse
}

Christopher Stone and Gene Mirus

\section{INTRODUCTION}

The Deaf community or sign language using communities manifest superdiversity and translanguaging in ways that intersect with and yet differ from other accounts of superdiversity. In this chapter we explore the historical context of the use of sign language and the emergence of sign language communities from a minority language community context. We use the emergence of the American Deaf community as an example that is typical of many western Deaf communities. We also explore transnationalism with global deaf communities and the emergence of superdiversity in Deaf spaces both in situ and technologically enabled.

We then turn our gaze to the case of a Deaf lawyer whom we interviewed. Here we examine schooling and language strategies used by the Deaf lawyer to gain access to a legal education. We describe the types of linguistic devices used by the lawyer and those used by others that he draws our attention to.

\section{HISTORICAL PERSPECTIVES}

For a fuller understanding of superdiversity in the world of deaf people, one must first discuss the history of linguistic oppression in the minority sign 'language' communities (traditionally known as deaf communities). Deaf people often struggle to maintain and protect their tradition in-group languaging, while contending with language policies created and enforced by a dominant 'language' group. Language policies can either threaten or support a minority 'language' community, at least trying to ensure that tradition linguistic features are transmitted to younger community members. Through time, language ideologies (Kroskrity, 2000) are negotiated at different levels and are constructed and re-constructed (Blackledge, 2000). The examination of power and identity among both minority and dominant 'language' groups is a prerequisite to understanding their respective language ideologies (Woolard, 1998).

From the late 19th century, deaf people were systematically denied access to visually accessible, naturally perceivable 'language' due to policies in educational institutions. These stemmed from ideological attachments to speech as the only natural modality for language 
(e.g., Bell, 1883). This has led many 'American Sign Language' (ASL) users in the US deaf community at-large to feel deaf people who grow up with only speech (and Cued Speech) are socially disenfranchised, hence ASL users' resistance to being colonized (cf. Ladd, 2003) by 'hearing' speakers with respect to the modality of linguistic features used, i.e. manualgestural rather than speech-tract-gestural. Since the 1960s sign language linguistics has approached sign language as a manual-gestural manifestation of language. Many of the analyses of spoken language, i.e. the language driven psychomotor control of the 'gestures' or bodily movements made by the speech-tract have given us the analysis of one modality of language. By analysing the manual-gestural bodily movements used to generate sign language we are able to identify language phenomena that are either present in language generally (i.e. in both modalities, speech and sign), or modality specific (speech vs sign).

For most of the nineteenth century in America, deaf education was what today's deaf community would consider the educational ideal. Yale divinity scholars of the time held positive views of sign language (Baynton, 1996); they saw sign language as pure and believed it was close to a divine or original language. In fact, these scholars observed that the syntactic structure of ASL was comparable to Latin and Greek. Academia at the time held Latin and Greek in high regard, seeing the two languages as pure, unlike the 'fragmented' Romance languages. Since Christian doctrines posit that humans began as flawless beings (e.g., Adam and Eve) and worsened overtime, the divinity scholars' theory held that a purer language made for a closer relationship between man and God. This belief supported the gathering of deaf people together to form communities in and around residential deaf schools, who passed on their local language features to shape what have been considered the 'regional dialects' of 'national' sign languages (Quinn, 2010).

At this time, sign language was prevalent among the deaf population. At residential schools for the deaf across the US, over 40 percent of the teachers were deaf and used sign language. Despite what could be perceived as a golden age in deaf education, a hindrance was imposed by two of the most revered minds of the time: Charles Darwin and Alexander Graham Bell. Darwin proposed that mankind started as primates and was actually evolving, thus contradicting Christian doctrine that mankind was created by God in its present form. Darwin's theory of evolution was largely misinterpreted by the public. People began to see sign language as a gestural language used by beasts; it was viewed as animalistic and backward.

From Darwin's theories emerged a politics of sexuality adopted by the medical establishment and concerned with "the art of determining good marriages, of inducing the 
desired fertilities, and of insuring health and longevity of children" (Foucault, 1978). Medical practices emphasized normality rather than health (Foucault, 1977). Professionals experimented with "curing" deaf people by pouring liquids in the ear and administered other physically painful and harmful "treatments" including fracturing the skull and inserting needles into the ear (Lane, et al. 1996).

Alexander Graham Bell headed the Eugenics section of the American Breeders Association, later called the American Genetics Association. Even though Bell used signed language with his deaf mother and deaf wife, the Association promoted a world-wide movement against signed languages. Bell claimed signed languages were responsible for the congregation of deaf people, causing them to marry each other and ultimately create a new variety of humans (Lane, et al., 1996). He endorsed having each deaf child raised and taught with hearing children to prevent further deaf congregation (Baynton, 1996). This assimilationist approach aimed to eradicate sign languages and the people associated with their use. It is worth noting that some of the education systems adopted some of the linguistic features of sign language to educate deaf children in the majority language, often coarticulating manual signs from a sign language with spoken language words. When formalised at a national level this often meant using the manual lexical signs of a specific region (e.g. the use of 'the green book' in Australia) to ease learning by non-signing 'hearing' teachers.

During this period, many fell victim to the hearing-imposed, non-signing, speech-only approach. This anatomo-politics (Foucault, 1978) involves fixing deafness by precluding sign languaging and imposing rigorous speech therapy, in some cases this also precludes the use of co-speech manual gesturing. Examples of bio-politics and politics of sexuality include sterilization of 17,000 deaf individuals under Hilter's Nazi Germany (Biesold, 1999), and the purposeful segregation/mainstreaming of deaf children to prevent endogamous marriages. For a long time, non-signers in positions of power have developed policies that determine how deaf children are forced to communicate. These policies often deny deaf children the use of ASL. One example is the implementation of oralism (discussed in Ladd, 2003) a philosophy whose premise was to make deaf children and adults 'pass' as hearing individuals, which has dampened the lives of many deaf individuals (O'Connell, 2016).

Oralism turned into a movement and became widespread worldwide in the aftermath of the Second International Congress on Education of the Deaf in Milan, Italy in 1880. This speechonly approach proved to be demoralizing for many deaf people. Deaf people who learned 
ASL later in life often state that they feel emancipated from the speech-only approach used in their daily lives.

After World War II, the Deaf working class developed strong social cohesiveness across the nation by creating physical spaces that were Deaf-owned and -managed, known as Deaf clubs. These Deaf places are tradition sites for sign languaging, often with Deaf clubs being geographically located near to Deaf schools either in the same town or city, or the nearest town or city to a residential school established in a rural area. Here deaf school leavers would congregate many nights of the week much like those attending working men's clubs, using the local/regional 'language'.

National boundaries, as with spoken languages, often define a 'national' sign language that is understood to be comprised of the numerous local/regional variants. Traditional sports competitions through school and then national structures such as the National Association of the Deaf (US) or the British Deaf Association (UK) bring sign languaging deaf people together who use different local/regional sign 'languages', this constellation is then understood to be the repertoire of linguistic features available to the national sign language bounded by geographical borders however transient these deaf spaces (Kusters, 2009) might be.

Today, access to technology, among other things, has resulted in an increased use of shared ephemeral 'deaf spaces'. As rhetoric in the U.S. encourages acceptance of other aspects of human diversity, deaf people continue to struggle to defend their culture and identity. We also see these deaf spaces being more frequent at a transnational level such as quadrennial events like the Deaflypmics (originally the Silent Games started in Paris 1924) and the World Federation of the Deaf congress (see Haualand, Solvang and Breivik, 2015).

However, in these ephemeral sign languaging spaces at a local, regional, national and transnational level, different linguistic and manual-gestural features are used, e.g. manual lexicon, fingerspelling, pointing, mouthing, etc. These Deaf spaces act as intersections between those who grew up using a local/regional/national sign language, those who arrive from elsewhere who also grew using a different local/regional/national sign language and those who have learnt a sign language. As these Deaf spaces shift and change with different participants the language features and sign languaging that occurs in those Deaf spaces begins to demonstrate elements of superdiversity often known as 'International Sign'. There is evidence of this kind of translanguaging dating back to the Paris 'Deaf Mute' [sic] banquets hosted to philosophise on deaf ontology (see Mottez,1993). Today, this 
superdiverse translanguaging is further strengthen by the use of videoconferencing technology such that this translanguaging exists beyond these in situ gatherings.

Whereas traditional Deaf spaces such as Deaf clubs would have exerted a levelling effect on the sign languaging that occurred within the local community, we see that national and transnational use of videoconferencing technology promotes diversity and translanguaging. Some key transnational initiatives such as Frontrunners, brings young adult deaf leaders together to support their leadership development. This initiative promotes translanguaging and enables the communicative use of a variety of language features in situ and later via videoconferencing to be used not only for communication but also to demonstrate group identity.

Anecdotally, different cohorts of Frontrunners report differing uses of 'International Signing' between the cohorts often due to the different nationalities in each cohort. This begins to show the diversity we see at a transnational level, even so with antidiscrimination legislation at the local, national and international level deaf mobility is ever increasing such that we often have settled Deaf communities in different countries, such as Mexican Sign Language (LSM) users in some US cities and Lithuanian, Polish or Czech Sign Language users in London, etc.

\section{The American Deaf Community}

The past 30 years show that the policy on the training and education of American deaf children has never been truly static: residential school enrollments continue to dwindle, deaf children are being assimilated into public schools and parents of deaf children are being encouraged to provide their children with cochlear implants, surgically inserted electronic devices that provide the sensation of hearing, useful to varying degrees (Thoutenhoofd, 2000). Policies, both language and social, developed and enforced by hearing educators have often been at odds with the agenda and expectations of the American deaf community. And the lived experience of being deaf often brings deaf people together with a desire to communicate in a 'least restrictive' way this is where we begin to see diversity and superdiversity emerge within deaf communities.

Residential schools for deaf children across the country helped to shape Deaf identity by bringing deaf people together, allowing collective cultural and linguistic definition as well as united resistance and struggle (Ladd, 2003). The formation of the American Deaf community is attributed in great part to schools for the deaf. Children were placed together; 
consequently, they shared common linguistic and social experiences. When they left high school, they became members of the larger deaf community outside the school.

The advent of mainstreaming deaf children in public schools in the United States with the 1977 federal law mandating that deaf children have the right to the 'least restrictive environment' (Ramsey, 1997). The educational environment of residential schools was considered 'restrictive' under that law because students were 'devoid' of access to the 'hearing' world. Thus, parents placed their deaf child in the public school closest to home, with interpreting services provided.

This law and the philosophy of oralism were both, in part, reactions to the belief that the deaf community isolated themselves from the larger society (Fjord, 1996). This viewpoint resulted in the diaspora of deaf children across the country, mainstreamed and lacking access to a sign language model and thus communicative interactions with their hearing peers often resulted in failure (Keating and Mirus, 2003). Furthermore, some schools disallowed social contact among deaf children during lunch, breaks, and class time (pc. Coco 2001). The intention was to 'encourage' each deaf child to learn from and assimilate into the community of hearing children, thus ultimately disrupting the formation and maintenance of deaf communities and sign languaging. As this practice continues today, mainstreamed deaf children do not lack access to the hearing world. Instead, they lack access to the deaf world and often have a reduced linguistic repertoire because of this. It does however, result in nontraditional linguistic features being used within sign languaging context, especially when orally educated deaf children seek out the Deaf community in later life. This represents one part of the emerging superdiversity in the Deaf community.

At least ninety percent of deaf children are born to hearing parents (Mitchell and Karchmer, 2004) who seek advice from medical professionals who endorse the medicalization of deaf children (Lane, et al., 1996). This has led to a dramatic increase of cochlear implants since their inception in the 1980's. Stigmas often develop against those not taught signed language such as implantees who are likely to be isolated from other deaf children (see Goffman, 1963 for a general discussion of stigma within a community). This technology has resulted in endangerment of signed language and even sign languaging, with a likely decline in the number of signed language users in the next generation. In addition, recent mappings of deaf genes discovered through genetic research have further increased endangerment. And yet we see that this brings out two different reactions within the Deaf community, one of language purism and the other of embracing translanguaging. 
Language contact and language policies created by hearing education professionals teaching literacy skills have, in some countries, resulted in a sign system that orders signs according to the syntactic rules of a spoken language. Examples of this kind of system include Signing Exact English (SEE) or Signed Swedish. Such systems have been described as difficult for deaf children to understand because they fail to take advantage of spatial resources available to languages in the visual-manual modality. They bring different linguistic features together trying to maximise multi-modal features, e.g. manual signs, mouthing of spoken language words with or without sound, fingerspelling of words, etc. Although this has the potential to change and/or increase the repertoires of deaf children, research suggests this is not necessarily the case. This exposure in education allows for the acceptance of a variety of linguistic features in the classroom and later the university lecture hall to support the deaf learner. This will be discussed later within the context of deaf lawyers and the linguistic features the use to learn and discuss the law.

\section{Rhetoric and Resistance}

According to Jankowsi (1997), some deaf people used the rhetoric of "crucifixion" (in the sense of Foucault, 1977) to represent linguistic oppression imposed by hearing people who support the eradication of sign languaging. Jankowski referred to Foucault's idea that the "political field" is the body and that "(p)ower relations have an immediate hold on the body; they invest it, mark it, train it, torture it, force it to carry out tasks, to perform ceremonies, to emit signs." Another example of 'anatomo-politics', here hearing people impose their glotticentric views, endorsing an ideology which supports the idea of 'crucifying' signers to stop languaging from the arms and hands, faces and body.

The dominant social ideology holds that the deaf community is malleable (Lane et al., 1996). This malleability leads to continued subjugation from the dominant party - constantly requiring speech production and lip-reading, despite deaf individual's inability to hear, and preventing them access to signed languaging despite being a defining component of the deaf social identity.

Davis (1995) argues that Stalin's definition of nationality closely fits the deaf community. This includes: 1) common language, 2) a stable community, 3) a territory, 4) economic cohesion, and 5) a collective psychology and character and not as something essentialist, but as historically constructed. The deaf community has a common set of linguistic features, a stable community, and a collective psychology and character. Deaf people's construction of their own nationality does not correspond with preconceived notions or assumptions on 
nationality generally, thus, the American Deaf community is constantly pressured by the dominant speaking society (Lane 1993).

As previously asserted, the social identity of deaf people exists primarily through signed languaging. Per Gumperz and Cook-Gumperz (1982), an ethnic group that has a common communicative history will have preconceived negotiation strategies that will be shared and transmitted. Considering the survival of ASL in the past 100 years under the oralist regime, the languaging preservation mechanism used by deaf communities aligns well with this. For example, in efforts to document and preserve ASL, The National Association of the Deaf beginning in 1913 with George W Vediz, recorded signers on film.

Like other language communities, the Deaf community has politicized ASL. Research is used to maintain its status and respect. And, the deaf community downplays the encroachment of invented communication systems with tactics like creating parodies. For example, one might mimic Signing Exact English by appearing victimized and unintelligent and signing non-grammatical questions like, "HOW IS YOU?" One might respond, "I IS THE FINE." As the response is grammatically incorrect in ASL and atypical in English, the response is often perceived as funny. Many hearing parents and professionals have the mistaken assumption SEE provides structured access to English, this parody, though exaggerated at times, highlights the misassumption. So as with other communities the notion of 'language' is reified and certain features are expected to be entrenched if one is using 'ASL'. With traditional transmission patterns changing the language entrenched by younger generations and the linguistic features used highlight the diversity and translanguaging emerging within Deaf communities.

\section{Linguistic Oppression Within the Deaf Community}

There seems to be linguistic oppression even within the deaf community. Research with regard to the deaf community's history and use of ASL is abundant and primarily whiteoriented (e.g., Lane, Hoffmeister and Bahan, 1996; Padden and Humpheries, 2005). Given the diversity within the deaf community, it is surprising how little research has been done on groups marginalized within the community. The relative lack of scholarly inquiry into, for example, deaf-blind people (Collins and Petronio, 1998) who use more tactile linguistic features (Edwards, 2014), or 'oral' deaf people, who have been educated languaging within the spoken rather than signed modality. This may stem, in part from the fact that Deaf Studies is quite new, that ASL was recognized as a 'language' just fifty years ago, and because of politically motivated discursive choices that have put the deaf community in opposition to 
"disabled" people. This distinction has had considerable benefit in terms of increased recognition and understanding of deaf people as a cultural entity.

For ASL users, recognition has helped reduce the perceived stigma by outsiders to the community, e.g., people who are not deaf. This collective construct of deaf identity has been and, in some cases continues to be, incompatible with different communication systems, and has led to the marginalization of certain groups. For example, segregation of deaf Black children in the U.S resulted in the creation of Black American Sign Language (Maxwell and Smith-Todd, 1986). It is true however that much of the debates on defining a specific 'language' as a 'nation' forming vector also holds true for the deaf such that what is labelled as 'American Sign Language', could equally be seen as a collection of regional or local 'languages' whose label is defined by territorial political boundaries rather than by other concerns.

Having described the sociolinguistic context of sign languaging communities we will now focus on sign languaging deaf lawyers in the US.

\section{CORE ISSUES AND TOPICS}

Ethnographic studies of language practices involve describing language in its social setting, understanding the range of language activities within a society, and looking at how language is performed (Bauman and Sherzer, 1974). Linguistic ethnography studies examine the communicative situations where specialized signs have emerged, e.g., deaf attorneys, are rare. As Gibbons (2004: 286) states 'the law and its practitioners have developed a range of unique legal concepts, and these can be expressed efficiently only by using legal jargon.' And yet is it only in recent history, due to better access to educational institutions, that we see sign language using deaf people qualifying as lawyers and practising the law. This institutional interface is of interest to us.

Here we look at various phenomena sign languaging deaf lawyers, as conversationalists used to making communicative adjustments, use for legal jargon or concepts. This can help better understand the role of external influences, e.g., contact from ASL, spoken English, Latin, etc. While interviewing a deaf lawyer, as part of a larger project, he readily described the various linguistic strategies which he (and several other deaf lawyers) employed when sign languaging.

Central to linguistic ethnography is understanding the various ways in which people use language under particular psychological, social, and historical conditions. We are interested in understanding what the conditions are for deaf community lawyers who are now starting to 
use specialized legal signs and what it might take for standardization in the use of legal signs to occur, i.e. will there be a levelling effect within this group or will the nature of the global deaf world and technology such as videoconferencing promulgate superdiverse translanguaging. Initially we will look at form insofar as it can provide insight into and a better descriptive account of the variation in linguistic resources available in human communication.

\section{Layering of linguistic resources}

Sign languages comprise of a variety of linguistic features that co-occur to form words, sentences and discourse. Sign phonemes are described by features such as handshape, movement-hand internal, movement-path, place of articulation, etc. (Brentari, 1998). As expected by duality of patterning, morphemes are comprised of these phonemes although we also see the co-articulation of a set of mouth gestures (Boyes-Braem and Sutton-Spence, 2001) that have adjectival and adverbial properties.

Mouthing is a language feature enabling the borrowing of words from spoken languages into sign languages, either partially or fully articulated on the lips during the production of a manual sign element. The mouthing might spread across several manual signs such as a noun phrase or verb phrase which might influence the full or partial articulation of the 'borrowed' word element. Some of these mouthings may well share different semantic representation to their manual components (Vinson et al., 2010).

Finally, most sign languages have hand configurations (either one or two handed) that represent orthographic systems, known as fingerspelling (see Sutton-Spence, 1994 for a comprehensive review). Fingerspelling is often considered non-native lexicon in sign languages (Brentari and Padden, 2001) in that their phonological constrains and rules differ from those of the other lexicon (core and non-core).

We also need to understand that humans have two hands, they can articulate two different manual elements that can also have a mouthing and other facial grammar co-articulated simultaneously. This simultaneity is exploited when sign languaging and can also include gestural elements of a non-linguistic nature, also known as depiction (Liddell, 2003). Coarticulation is ever present in sign translanguaging, as we will describe below, where there are expectations of a variety of 'language' features being brought together. These codeblends (Emmorey et al., 2008) are complex and depending on the individual may include voiced elements too, although this is beyond the scope of this chapter. 


\section{Co-occurrence of linguistic features}

We will now look at the occurrence of specific linguistic features used by deaf lawyers in the US to discuss the law. There are several strategies that are adopted and different language features that are used to express these concepts. We will look at fingerspelling, then compounding and then look at the role of mouthing (English and Latin) in sign translanguaging.

\section{Fingerspelling}

Within many sign languages fingerspelling is often articulated in two different ways, the first is often referred to as fingerspelled signs where the orthographic pattern is phonologically reduced, e.g. the fingerspelled sign \#bus in ASL is not produced as -B- -U- S- but with the partial articulation of the -U- which could be represent thus -B-u-S-. This reduced form has a corresponding reduction in the time taken to produce the sign. The second form of articulation is a full orthographic pattern with the full production of each hand configuration for each letter. This can still be produced at speed but each letter is enunciated.

Fingerspelling is a common way that some lexis enters sign languaging. This strategy can be common within educational contexts especially if education is being access via an interpreter, such as when students are mainstreamed, but is used more broadly as a translanguaging strategy. Fingerspelling is used to a greater or lesser extent by different communities across the US (and in sign languages across the world). This usage can differ across age, professional and region. For the deaf lawyers fingerspelling is used to quote and use both English and Latin legal terms. In our data we see legal terms being quoted and then compounds given (see below), but we also see some legal terms being fingerspell.

For example, estoppel is fingerspelled in a reduced phonological form and we see rea judicata fingerspelled but in a fully enunciated form. The first example 'borrows' from 'English' and the second from 'Latin'. Generally, we see that 'Latin' legal terms are fully enunciated whereas 'English' legal terms are reduced. This difference does not appear to be due to lack of knowledge or frequency of use per se, but it could be due to the less frequent articulatory pattern of fingerspelled 'Latin' words - the phonotactics of the words differ. What is clear is that both types of fingerspelling are used by deaf lawyers for in-group talk amongst lawyers and with interpreters within education settings.

\section{Compounding}


In looking at and documenting signs used by deaf lawyers, it is useful to see what signs are used and to see whether this follows similar patterns observed in historic language change, i.e. although these appear to be in-group talk the compounding process itself is not altogether novel. In looking at the literature in regards to historical change in spoken languages (e.g., Sapir 1921) and in ASL (e.g., Frishberg 1975), change often happens in response to the need for efficiency of production, i.e. phonological reduction. For example, historically, the ASL sign GOLD was a compound of the signs EAR and YELLOW, but now that compound has phonologically reduced to a single sign in response to pressures for smoother and quicker movement.

For the deaf lawyers we see similar compounding occurring but we also see that part of this compounding is in situ language planning, as one of our informants explains:

Most of the time when establishing a new sign for a legal concept, so if I established a new sign or developed a new sign, I felt that it had to have a logical relationship to the meaning, it had to be easy to remember and repeat, that it should not require an exclamation when it was being signed... this meant that along the way some signs were tweaked and so it continually evolved

These neologisms are clearly meaning driven compounding but from a position of understanding the law, the terms that are used, and the different language resources that can be co-articulated. It is not clear whether the use of all the resources and their co-articulation are planned, especially when we consider mouthings be they partial or full, this will however be considered below.

There are several examples of compounds that we can see in our data. When each were produced in interview the metalinguistic and legal knowledge was given by fingerspelling, explanation and then compound. For example, we see one of our informants saying:

Injunction - it means you need to file something to stop all put something on hold... I try to think how to compound signs, for example FILE+STOP that's easy to remember and to reproduce so that when an interpreter heard the word injunction they could reproduce that compound, and when I signed FILE+STOP they could say the word injunction. This strategy did not require the addition of fingerspelling or an explanation 
Here we use the + to denote removal of the terminal hold for each sign (FILE and STOP) such that the production of each sign is phonologically reduced to produce the compound the reduction seen in the English words black bird and blackbird. Although the motivation for the neologism stems from wishing to express the notion of injunction in something that is more 'ASL' like.

Estoppel is also produced as a compound TALK+STUCK as is subpoena:

subpoena DEMAND+CALL again a compound it means a judge has filed a demand for you to attend court and you are required to show up so the compound could be either DEMAND+SHOW-UP DEMAND+CALL but the sign SHOW-UP doesn't make sense because the person subpoenaed hasn't come to court yet

Here we see that the informant is making clear meaning distinctions between the verb SHOW-UP and CALL such that the compound has clear rules in its formation.

Thus far the descriptions we see appear to be examples of tradition language contact rather than examples of translanguaging. Historically it could be said that in ASL the role of mouthing is dis-preferred, with fingerspelling often being articulated with no co-articulation of mouthings. In our data however, what is emerging is not only the use of fingerspelling (non-native lexicon) and compounding (of core lexicon) but also the co-articulation of mouthing as a linguistic resource which we shall now go on to describe.

\section{Mouthing}

Mouthings are the partial or full borrowing of spoken languages into sign language although their articulation is principally unvoiced and often the orthographic shape is mouthed, e.g. the word doubt might have mouthed articulation of the silent ' $b$ '. We can see from one of our informants that different language resources have the co-articulation of mouthings and occur both on fingerspellings and compounds.

We see that if a fingerspelling is fully enunciated then the mouthing moves towards being closer to fully mouthed. Even so it is worth reiterating that the mouthing component follows the prosodic rhythm of the fingerspelling - it is a hybrid form that is not part of an English speaker's repertoire. In this translanguaging we see the fingerspelled words that historically might have not had any mouthings at all now have mouthings and these include: injunction, estoppel, subpoena, jurisprudence, precedent, res judicata and jurisdiction. 
The compound words also have mouthings that delineate the compounds noun-phrase prosodic boundary. Here we will show the COMPOUND(mouthings), e.g.

ESTABLISH+BEFORE(precedent), CONTROL-AREA(jurisdiction) where the words in CAPTIALS are glosses for the ASL manual lexicon and the word in (brackets) represents the mouthing which might be partially or fully mouthed. We also begin to see the disambiguation of signs such as the tradition sign of COURT/JUDGE with the use of mouthings: COURT(court), COURT+ROOM(courtroom), HIT-GAVEL(judge), HIT-

GAVEL+DECISION(jurisprudence). And one of out informants noted that 'more and more people use the sign HIT-GAVEL(judge)' for judge rather than the tradition sign. This could be seen as the lexicalization of a depicted action what is also of interest is the co-articulation of the mouthing of English.

Again one of the important things to note here is that although the coding system we are using, i.e. COMPOUND(mouthings) reads as if these elements occur consecutively they are co-articulated. This co-articulation allows for a code-blend of an ASL manual element and an English or Latin mouthing element to be expressed and complement each other. This mechanism can also be used in other translanguaging moments when an ASL manual element might be co-articulated with a Spanish mouthing depending on the language resources of the individual (see Quinto-Pozos, 2008 for an analysis of the use of ASL, LSM, English and Spanish linguistic features of border town Deaf multilinguals).

\section{Negotiation of language}

One of the issues that arose with respect to translanguaging and the use of ASL, English and Latin linguistic features for legal talk amongst Deaf lawyers was the fact that although there is a Deaf lawyers network much of this discussion happens online and in written English. This means that what we see when Deaf lawyers come together during face-to-face interaction is an individual negotiation of understanding in the moment drawing upon, legal knowledge, legal experience and a variety of linguistic features such that in situ sign translanguaging occurs.

Part of the educational and work experience of Deaf lawyers is their interaction with sign language interpreters. As most sign language interpreters are late learners of sign languages language negotiation often occurs with the interpreters and this stems around the translanguaging that will be used to express legal concepts, as one informant explained: 
I've found that if the interpreter used initialised signs then they would also add an explanation where is by using a compound the meaning was contained within the sign and didn't need an explanation. If you consider that many legal terms have Latin roots and these roots often brought together as roots and affixes so by signing that way it worked out to be more expedient.

This metalinguistic awareness seems to be present at least to some extent in Deaf lawyers. There is also some acknowledgement of different linguistic resources that deaf people might bring to bear depending on the linguistic resources and repertoires they have available to them. There was mention of education influencing choices, 'Many Deaf people are taught 'orally'... not really native signers so not really in a position to understand ASL rules and grammar which leaves a few of us the others use a lot of initialised signs that does not feel natural to me' and yet this comment was by no means a negative slur on other deaf peoples translanguaging. The informant wished to acknowledge a different language experience than some others.

Our principal informant for this analysis is deaf from a deaf family raised using sign language in the home and during schooling. Their university education was provided in sign language during their undergraduate studies and via sign language interpreters during their legal studies. As a literate deaf person they bring a variety of resources to bear during their discussions of the law and their legal studies. Much of this demonstrates how written resources are then used within face-to-face interaction and especially with interpreters. The interpreters will also be bringing different linguistic resource into this interaction and the translanguaging in these moments require mutual agreement and reinforcement.

It is not clear that communities of practice are actually developing as deaf lawyers tend to be trained individually and there are very few work in practice together. That does not mean that some sign languaging strategies are not passed on to others. As our principal informant says:

I did share some of my vocabulary with several other who were starting law school just as I was finishing law school. I explained my system and they liked it as they used the same interpreters as me. They were in two different law schools in the same city. Many of my interpreters were trained so they picked up that lexicon, I explained my theory and they continued to use that. 
This demonstrates the planning element of the translanguaging that occurs. This motivated use of language resources may well be different than the motivations we see in other communities. The role of interpreters and their place in the translanguaging that occurs within deaf communities is not unproblematic and yet this is often led by deaf people making specific choices around how they want discuss new areas of knowledge and expertise and the linguistic resources they can bring to bear.

\section{NEW DEBATES}

With the greater social mobility of deaf people, such as better access to education and employment opportunities, sign languaging is occurring is ever increasing domains. The changing face of those using sign language includes those who would not traditionally engage in sign languaging such as, orally educated deaf people and 'hearing' people with no family members both of whom often learn sign languages as a second language bringing other linguistic features and resources to bear in their language use

Although some of the tradition routes of language transmission still exist in the American Deaf community (i.e. deaf families) other avenues such as deaf places (residential deaf schools and deaf clubs) are closing down or in decline when compared with 20 or more years ago. New deaf spaces including technological spaces are emerging such as Facebook groups that use video, YouTube and Vimeo amongst others. As these spaces emerge they are also being used for professional networks at a regional, national and transnational level.

Deaf people are also gaining greater access to education globally and better technology to enable transnational communication. As mentioned above, some transnational education, such as Frontrunners, creates networks of deaf people from many countries who engage in transnational sign translanguaging. As there are few deaf lawyers generally and transnational (e.g. the European Union of the Deaf) and international (e.g. the WFD) organisations often create networking opportunities for deaf professionals within transient deaf transnational sign translanguaging spaces it is feasible that the occurrence of sign translanguaging will increase in the future both in situ in a transient deaf space and over technology in a virtual deaf space.

\section{SUMMARY}

This chapter has discussed the language tensions of experienced by the deaf community over the last 100 years. Deaf sign language users have resisted the enforced change of modality of language production and linguistic features. With the decrease in deaf teachers of the deaf, the mainstreaming of deaf children and oral education tradition routes for language 
transmission are changing, notwithstanding that the congregation of deaf people be they in deaf places or transient deaf spaces still enable the transmission of tradition. In the last 100 years transient transational deaf spaces at the Deaflympics and in the last 50 years the WFD, have emerged that engage in in situ sign translanguaging. Technology now also allows for the virtual deaf spaces and virtual sign translanguaging that can either occur face-to-face or is permanently recorded with professional networks that are emerging at a regional, national and transnational level.

The mainstreaming of deaf children is one of the reasons for superdiversity to emerge in the sign language using communities. Greater numbers of deaf people finding the deaf communities as young adults (or older) brings greater numbers of sign language users with sign languages as a later learned language. There are also greater numbers of 'hearing' people learning sign language as a second language. These second language users bring different linguistic features to sign languaging interactions and so translanguaging begins to emerge in face-to-face interactions.

Educated deaf people need to access law school via interpreters and this requires translanguaging to occur during the interpreter-mediated education. For us this is not about education per se but rather that expertise for Deaf individuals, who are required to interact with non-signing peoples and draw upon knowledge from mainstream knowledge production, draw upon resources within their own language as well as other languages to perform their expertise. While there are specific ways in which linguistic resources manifest when a sign language using deaf people deploys them this is ostensibly a phonetic issue: an 'ASL' user will spell the term rea judicata using an ASL fingerspelling phonetic realisation of this term in much the same way in which a US lawyer would pronounce the Latin term in an ‘American English' phonetic realisation.

Our principal informant lead this process by planning the language they used and engaging with their interpreters so that the interpreters also used their language. The co-articulation of linguistic resources enabled traditional linguistic resources (fingerspelling and the compounding of manual lexicon) to be codeblended with partial of full mouthings of both English and Latin lexicon. These codeblends show the types of translanguaging that is emerging in the language use of American deaf lawyers. Translanguaging appears to include codeblending, but extends this further than just co-articulating the spoken component of the majority spoken language. Translanguaging in this context is rather the drawing upon the linguistic resources of ASL with several other languages within a discourse and these could 
be sign languages, written language via fingerspelling or spoken languages via spoken mouthing components.

\section{FURTHER READING}

Keating, E. and Mirus, G. 2003. American Sign Language in virtual space: Interactions between deaf users of computer-mediated video communication and the impact of technology on language practices. Language in Society 32: 5 pp. 693-714

This article describes how new communication technologies have created new contexts for social interaction and new challenges for understanding the role of technology in human activity, particularly in altering spatial relationships of interaction. The article focuses on ways how technology is influencing social interaction and language use among a visual language community, the Deaf community, in the U.S.

Stone C and Woll B (2008) DUMB O JEMMY and others: Deaf people, interpreters and the London courts in the $18^{\text {th }}$ and $19^{\text {th }}$ centuries, Sign Language Studies, 8 (3), 226 - 240. doi: $10.1353 /$ sls.2008.0009

Woll B and Stone C (2013). Deaf people at the Old Bailey from the 18th century onwards. In M. Freeman and F. Smith (eds) Law and Language, Current Legal Issues (Vol 15). Oxford: Oxford University Press.

The two articles give a historic perspective on the arguments around the use of sign language and gesture in the UK courts. These focus more on the lay person's experience in court and demonstrate the permissive nature of the courts historically towards sign languaging and deaf people. It is clear that historically some of this languaging would have included gesture repertoires as well as sign languaging.

\section{NOTES}

Acknowledgements. We would like to express our grateful acknowledgement to the Spencer Educational Foundation for funding this project.

\section{REFERENCES}

Bauman, R. and Sherzer, J. (eds) (1974) Explorations in the ethnography of communication. Cambridge: Cambridge University Press.

Baynton, D. 1996. Forbidden Signs: American Culture and the Campaign Against Sign Language. Chicago. The University of Chicago Press. 
Bell, Alexander Graham. 1883. Upon the Formation of a Deaf Variety of the Human Race, paper presented to the National Academy of Science.

Biesold, H. 1999. Crying Hands: Eugenics and Deaf People in Nazi Germany. Washington, D.C.: Gallaudet University Press.

Blackledge, A. 2000. Power relations in the social construction of 'literacy' and 'illiteracy': the experience of Bangladeshi women in Birmingham. In M. Martin- Jones \& K. Jones (Eds.), Multilingual Literacies (Vol. 10, pp. 55-70). Amsterdam: John Benjamins Publishing Company.

Boyes Braem, P. and Sutton-Spence, R. 2001. The hands are the head of the mouth. Hamburg: Signum Press.

Brentari, D. 1998. A Prosodic Model of Sign Language Phonology. Cambridge, MA: MIT Press.

Brentari, D. and Padden, C. 2001. A lexicon with multiple origins: Native and foreign vocabulary in American Sign Language. In D. Brentari (Ed.), Foreign vocabulary in sign languages: A cross-lingusitic investigation of word formation. Mahwah, NJ: Lawrence Erlbaum Associates.

Collins, S., and K. Petronio. 1998. What Happens in Tactile ASL? In Pinky Extension and Eye Gaze: Language Use in Deaf Communities, ed. C. Lucas, 18-37. Sociolinguistics in Deaf Communities, vol. 4.Washington, D.C.: Gallaudet University Press.

Davis, L. J. 1995. Enforcing Normalcy: Disablity, Deafness and the Body. London: Verso. Emmorey, K., Borinstein, H. B., Thompson, R., and Gollan, T. H. (2008). Bimodal bilingualism. Bilingualism, 11(1), 43-61.

Fjord, L. L. (1996), Images of Difference: Deaf and Hearing in the United States. Anthropology and Humanism, 21: 55-69. doi:10.1525/ahu.1996.21.1.55

Foucault, M. 1977. Discipline and punish: The birth of the prison. Translated by A. Sheridan. New York: Pantheon Books.

Foucault, M. 1978. The history of sexuality: An introduction. Vol.1. Translated by R.Hurley. New York: Pantheon Books.

Frishberg, F. 1975. Arbitrariness and Iconicity: Historical Change in American Sign Language. Language, 51 (3), 696-719

Gibbons, J. (2004) Language and the Law, in The Handbook of Applied Linguistics (eds A. Davies and C. Elder), Blackwell Publishing Ltd, Oxford, UK. doi: 10.1002/9780470757000.c 
Goffman, E. 1963. Stigma: Notes on the management of spoiled identity. Englewood Cliffs, NJ: Prentice-Hall.

Gumperz, J. and Cook-Gumperz, J. 1982. "Introduction: Language and the communication of social identity”. In J.J. Gumperz (ed.), Language and social identity. Cambridge: Cambridge University Press.

Haualand, H., Solvang, P. K. and Breivik, J. 2015. Deaf transnational gatherings at the turn of the twenty-first century and some afterthoughts. In Friedner, M. and Kusters, A. (Eds.) It's a small world: International Deaf spaces and encounters (pp. 47-58). Washington, DC: Gallaudet University Press.

Jankowski, K.A. 1997. Deaf Empowerment: Emergence, struggle, and rhetoric. Washington, D.C.: Gallaudet University Press. I

Keating, E. and Mirus, G. 2003. American Sign Language in virtual space: Interactions between deaf users of computer-mediated video communication and the impact of technology on language practices. Language in Society 32: 5 pp. 693-714

Keating, E. and Mirus, G. 2003. Examining Interactions across Language Modalities: Deaf Children and Hearing Peers at School. Anthropology and Education Quarterly 34(2):115135.

Kroskrity, P. V. 2000. Language ideologies in the expression and representation of Arizona Tewa ethnic identity. In P. Kroskity (Ed.) Regimes of language: ideologies, polities and identities. pp.329-59. [Accessed June 2016] https://sarweb.org/media/files/sar_press_regimes_language_chapter9.pdf

Kusters, A. 2009. Deaf on the lifeline of Mumbai. Sign Language Studies, 10(1), 36-68.

Ladd, Paddy. 2003. Understanding Deaf Culture: In Search of Deafhood. Buffalo: Multilingual Matters.

Lane, H. 1993. The Mask of Benevolence: Disabling the Deaf Community. New York: Knopf. Lane, H., Hoffmeister, R., and Bahan, B. 1996. A journey into the deaf-world. San Diego, CA: Dawn Sign Press.

Liddell, S. K. 2003. Grammar, gesture, and meaning in American Sign Language. Cambridge: Cambridge University Press.

Maxwell, M. M., and Smith-Todd, S. 1986. Black Sign Language and School Integration in Texas. Language in Society 15(1), 81-93.

Mitchell, R. E. and Karchmer, M. A. 2004. Chasing the mythical ten percent: parental hearing status of deaf and hard of hearing students in the United States. Sign Language Studies, 4(2), 138-163. 
Mottez, B. 1993.The Deaf-Mute Banquets and the Birth of the Deaf Move- ment. In Looking Back: A Reader on the History of Deaf Communities and Their Sign Languages, ed. R.

Fischer and H. Lane, 143-55. Hamburg: Signum.

O'Connell, N. P. 2016. "Passing as normal": Living and coping with the stigma of deafness. Qualitative Inquiry, 1077800416634729, first published on March 21, 2016 as doi:10.1177/1077800416634729

Padden, C. and Humphries, T. 2005. Deaf in America: Voices from a culture. ( $\left.2^{\text {nd }} \mathrm{ed}.\right)$ Cambridge, MA: Harvard University Press.

Quinn, D. 2010. Schoolization: An account of the origins of regional variation in British Sign Language. Sign Language Studies, 10(4), 476-501.

Quinto-Pozos, D. 2008. Sign language contact and interference: ASL and LSM. Language in Society, 37, pp.161-189.

Ramsey, C. 1997. Deaf children in public schools: Placement, context and consequences. Washington, DC: Gallaudet University Press.

Sapir, E. 1921. Language: An introduction to the study of speech. New York: Harcourt, Brace.

Sutton-Spence, R. 1994. The role of the manual alphabet and fingerspelling in British Sign Language. Ph. D. diss, University of Bristol.

Vinson, D., Thompson, R. L., Skinner, R., Fox, N. and Vigliocco, G. 2010. The hands and mouth do not always slip together in British Sign Language: Dissociating articulatory channels in the lexicon. Psychological Science, 21(8), 1158-1167.

Woolard, K. 1998. Introduction: Language Ideology as a Field of Inquiry. In B. Schieffelin, K. Woolard \& P. Kroskrity (eds.) Language Ideologies: Practice and Theory. New York: Oxford University Press. 